\title{
Common Diseases of Road and Bridge Engineering and Application of Construction Treatment Technology
}

\author{
Weiwei Li*, Yiguo Xue, Yanliang Du, Xinqiang Zhang \\ Shandong University, Jinan, China \\ Email: vivienli0914@icloud.com
}

\begin{abstract}
The purpose of this study is to understand the common diseases of road and bridge engineering and put forward the corresponding construction treatment technology. In this study, firstly, taking reinforced concrete bridges and roads as examples, several common diseases of road and bridge engineering are introduced. Then, the causes of these common diseases are analyzed. Finally, the control countermeasures of diseases of bridge and road are put forward. That is, the bottom plate of the large-area disease within the treatment range is outsourced with a steel plate, and the high-intensity grout is filled therein; all girder bottom diseases are repaired with acrylic mortar; for the treatment of other local diseases, the construction technology of crack sealing and grouting is adopted; and operation monitoring system is installed. The results show that these construction techniques can prevent and control the common diseases of bridge engineering to a great extent. Therefore, this study has some practical significance.
\end{abstract}

Keywords: Disease, construction treatment, bridge engineering, reinforced concrete, control

\section{Introduction}

In the process of using the bridge, due to the characteristics of the reinforced concrete structural material, the design and construction quality of the structure, the environment in which the structure is located, the conditions of use of the structure and the protective measures, the bridge will produce various damages or local damage or deformation $[1,2]$. Therefore, the bearing capacity of the bridge is insufficient, the performance is poor, and the durability can't meet the requirements. These damages and deformations are collectively referred to as bridge diseases [3, 4, 5]. Due to historical reasons, such as the low design load and discharge standard at that time, the lack of technical strength, the low level of design, construction technology, material, and equipment, etc., so that it needs to be repaired and replaced later, and similar situations are no exception in other countries of the world [6, 7]. Due to its large number, wide area and so many projects, the disease of concrete bridge has a serious impact on the safety and smoothness of transportation and the vast cost of repair has become a common concern of all countries in the world $[8,9]$.

With the development of transportation, the analysis and maintenance of bridge and road are very important $[10,11]$. The design standards are constantly improved, and the requirements on the service level of transportation operation are also increasingly high, a large number of roads and railways need to be built $[12,13]$. Bridges and roads are the chokes to ensure smooth traffic flow, and their carrying capacities are the key to connect all lines [14, 15]. Therefore, the requirements for them are getting higher and higher, and the construction task is more arduous. However, today's bridges and road construction projects have experienced many problems during construction and operation, and even engineering accidents have occurred [16, 17, 18]. In order to better repair, maintain, strengthen, and transform bridges and roads, it should collect basic data, fully understand and master the common defects and diseases of bridges and roads, provide the basis for the corresponding technical transformation, demolition and reconstruction, and find out the prevention and control measures to make the bridge and road cause develop faster and better [19, 20]. 


\section{Common Diseases of Reinforced Concrete Bridges and Roads}

The common diseases of reinforced concrete bridges and roads are as follows: honeycomb hole, which refers to the partial looseness of concrete, less mortar, more sand, and voids between stones, forming a honeycomb hole; pockmark, which refers to the partial lack of cement paste and roughness of the concrete surface, or there are many small pits, but no steel bars are exposed; water seepage, it refers to that the water on the concrete surface penetrates into the other side of the structure along the inside of the structure, which is mainly reflected on the lower surface of bridges and roads; void, which refers to a void in the interior of a concrete, partially without concrete, or a particularly large honeycomb, which occurs in reserved holes and embedded parts; crack, which refers to the phenomenon of incomplete separation between two or more parts of the remaining gaps, as shown in figure 1; peeling, which refers to the phenomenon that the concrete surface sand and cement slurry fall off and the coarse aggregate is exposed. If it is serious, the aggregate and the mortar covering the aggregate will fall off together, or the mortar on the concrete surface will flake off; exposed ribs, which refer to the phenomenon that the main ribs and stirrups in the reinforced concrete are not covered by the concrete, as shown in figure 2; free lime, which refers to the deposits that are exuded from the inside and attached to the outer surface, usually a white lime attachment; deterioration, which refers to the change of mechanical, physical or chemical damage on the concrete surface or the whole and constitutes the segregation of concrete components.

Under normal circumstances, the damage of bridges and roads starts from concrete cracks. The crack width of reinforced concrete structure mainly affects the durability of the structure. At the same time, with the development of crack width, the stiffness and bearing capacity of the structure will be reduced. After the occurrence of cracks, due to the intrusion of moisture or harmful gases, it will lead to corrosion of the steel bars and shorten the service life of the structure. Therefore, it is particularly important to detect the cracks of bridge and road.

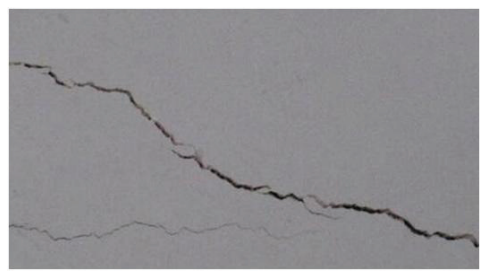

Figure 1. Crack in the bridge and road

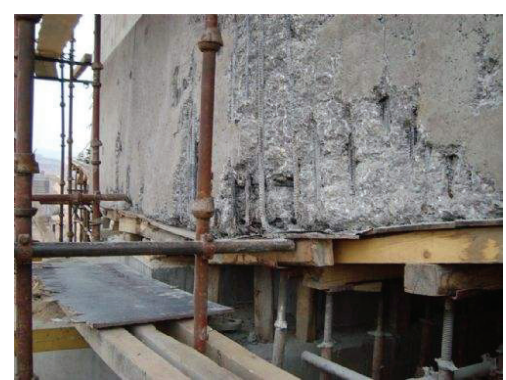

Figure 2. Exposed ribs

\section{Causes of Diseases of Bridges and Roads}

Bridges and road structures often form a variety of defects and damage during the progress of construction and use. Defects and damage are caused by many factors. Generally speaking, the root cause can be found from three aspects: design, construction, and external cause. In general, the types and causes of bridge and road defects are not necessarily single, sometimes a defect may be caused by several reasons. It is often difficult to find out the cause of a defect in a bridge or road that has been 
used for many years. Therefore, it is required that inspectors should have rich professional knowledge and be able to make comprehensive analysis and judgment through extensive inspection. For concrete Bridges and roads, the causes of defects are shown in table 1.

Table 1. Analysis of the causes of defects in concrete bridges and roads

\begin{tabular}{|c|c|c|}
\hline Classification & \multicolumn{2}{|c|}{ Detailed explanation } \\
\hline \multirow{3}{*}{ Design } & $\begin{array}{l}\text { Unreasonable } \\
\text { structure }\end{array}$ & $\begin{array}{l}\text { Unreasonable classification of structure type, form, span, etc. } \\
\text { Unreasonable section shape }\end{array}$ \\
\hline & $\begin{array}{l}\text { Calculation } \\
\text { error }\end{array}$ & $\begin{array}{l}\text { Wrong design criteria and conditions } \\
\text { Insufficient overall safety study } \\
\text { Wrong stress calculation } \\
\text { Calculate errors or omissions }\end{array}$ \\
\hline & $\begin{array}{l}\text { Incomplete } \\
\text { drawings }\end{array}$ & $\begin{array}{l}\text { Unreasonable arrangement of steel bars and prestressed steel } \\
\text { Insufficient structural reinforcement } \\
\text { Section shape problem, insufficient size } \\
\text { Not enough structural details }\end{array}$ \\
\hline Construction & $\begin{array}{l}\text { Poor } \\
\text { construction } \\
\text { quality }\end{array}$ & $\begin{array}{l}\text { Wrong construction method and sequence } \\
\text { Unskilled operator } \\
\text { Inadequate research on temporary projects } \\
\text { Imperfect construction management } \\
\text { Wrong material storage method }\end{array}$ \\
\hline & $\begin{array}{l}\text { Poor } \\
\text { material }\end{array}$ & $\begin{array}{l}\text { Poor concrete quality } \\
\text { Poor quality of steel reinforcement and prestressed steel } \\
\text { Unqualified material }\end{array}$ \\
\hline External cause & & $\begin{array}{l}\text { Increased traffic volume, increased vehicle model, and increased axle load } \\
\text { Accidents, such as reloading, falling, fire, etc } \\
\text { Natural phenomena, such as earthquakes, freezing, floods, landslides, etc } \\
\text { The impact of adjacent projects } \\
\text { Chemical action, such as seawater, sewage, base material reaction, etc }\end{array}$ \\
\hline
\end{tabular}

\section{Countermeasures for Prevention and Control of Bridges and Road}

\section{Diseases}

\subsection{External Steel Plate and Internal High Strength Grouting Material}

Drill holes in the concrete where there is a large area of damage. The purpose of the holes is to drill through the screws. After the holes are drilled, the bottom steel plate is laid, the steel plate is temporarily anchored after the screw is worn, and the grout hole (diameter $5 \mathrm{~cm}$ ) is drilled. The grouting hole should be selected at an appropriate position. The grouting pipe should be buried in the position where the grouting is not easy to reach, the periphery of the steel plate is closed, and the grouting material is poured. Since the cross-sectional size is too small, the grouting material is not easy to be filled and compacted. When closing the periphery of the steel plate, it should be noted that if the damage depth is less than $3 \mathrm{~cm}$, the sealing treatment is performed. In order to increase the bond between the grout and the steel plate, the bent steel bar should be pre-welded on the inner side of the steel plate before the steel plate is erected. The position of the bent steel bar should be staggered with the screw and arranged in the same form as the screw.

The process flow of outsourced steel plate is shown in figure 3. 


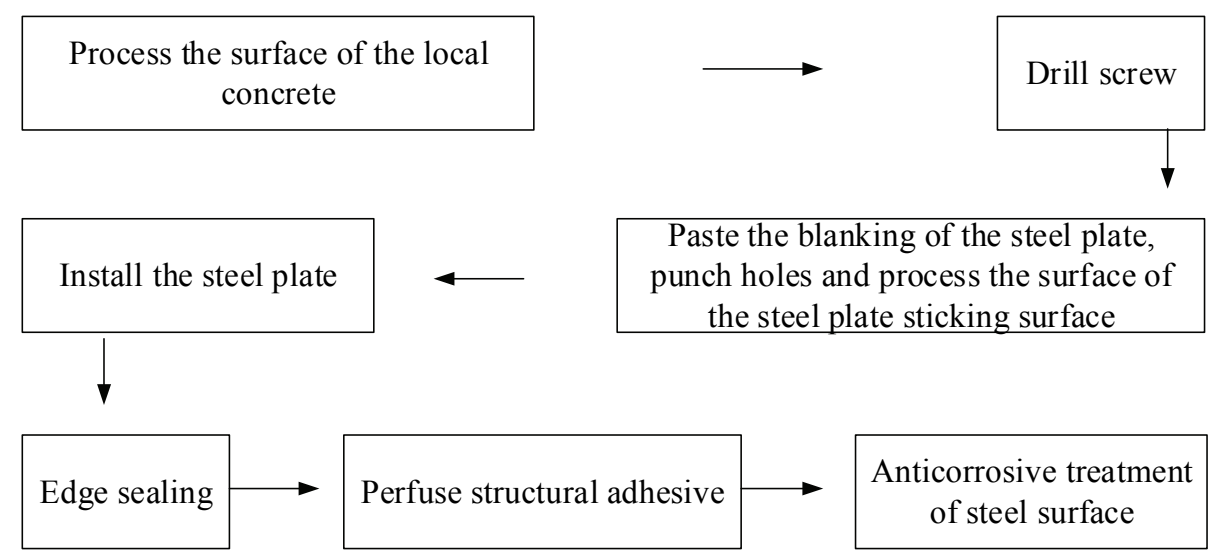

Figure 3. The process flow of outsourced steel plate

The mechanical properties and indexes of high strength grouting materials is shown in table 2 .

Table 2. Mechanical properties and indexes of high strength grouting materials

\begin{tabular}{c|c|c|c|c|c}
\hline Age & \multicolumn{2}{|c|}{1 day } & 3 days & \multicolumn{2}{c}{28 days } \\
\hline Compressive strength & \multicolumn{2}{|c|}{$\geqslant 22 \mathrm{MPa}$} & $\geqslant 40 \mathrm{MPa}$ & \multicolumn{2}{c}{$\geqslant 70 \mathrm{MPa}$} \\
\hline Standard dosage & $\begin{array}{c}\text { Reference water } \\
\text { consumption } \\
(\mathrm{L} / \mathrm{bag})\end{array}$ & $\begin{array}{c}\text { Initial } \\
\text { fluidity } \\
(\mathrm{mm})\end{array}$ & $\begin{array}{c}\text { Vertical } \\
\text { expansion rate } \\
\text { for 1 day }(\%)\end{array}$ & $\begin{array}{c}\text { Initial } \\
\text { setting time } \\
(\mathrm{min})\end{array}$ & $\begin{array}{c}\text { Round steel } \\
\text { wrapped strength } \\
\text { for 28 days }(\mathrm{MPa})\end{array}$ \\
\hline $2100 \mathrm{~kg} / \mathrm{m}^{3}$ & $3.5-4.0$ & $\geqslant 260$ & $\geqslant 0.020$ & $\geqslant 120$ & $\geqslant 6.0$ \\
\hline
\end{tabular}

\subsection{Repair All The Diseases at the Bottom of Beam with Acrylic Mortar}

For the apparent defect of the bulging and cracking at the end of the beam, the loose concrete is first removed. In order to avoid the cracking and peeling of mortar, ribbed steel mesh with a diameter of 5 $\mathrm{cm}$ and a spacing of $7.5 \mathrm{~cm}$ are first hung in the face of the disease with a length and width greater than $1.0 \mathrm{~m}$. Then, the acrylic mortar is applied. For diseases with small area and narrow width, acrylic mortar is directly applied for repair, and the application thickness shall be limited to the flat bottom of the beam according to the disease situation. When the application thickness exceeds $7 \mathrm{~mm}$, it shall be applied layer by layer to avoid prolapse affecting the construction quality.

In view of the large early-stage dry shrinkage performance of acrylic mortar, the early maintenance of acrylic mortar should be strengthened after construction. After the surface is slightly shrunk, spray maintenance measures are taken. After 24 hours, the usual sprinkling maintenance is carried out, and the sprinkling maintenance lasts for 7 days. After the sprinkling maintenance, the acrylic mortar reaches a natural dry state. If the repair surface is in the position of tuyere and direct sunlight, the maintenance should pay special attention to shading and moisturizing; if the surface of the repaired concrete is curved or inclined, the order from low to high shall be followed when applying pressure.

\subsection{Other Local Disease Treatment}

First, crack disease. when the width of crack is above $0.15 \mathrm{~mm}$, grouting and coating of protective materials are adopted for such cracks; when the crack width is within $0.15 \mathrm{~mm}$, the crack shall be closed immediately during grouting and no other treatment measures shall be taken.

Among them, the crack treatment technology is divided into two categories. First, crack sealing construction technology. For cracks with a width of less than $0.15 \mathrm{~mm}$, the wire brush is used to clear the floating slurry around the cracks, and then the press is used to blow the dust in the cracks clean. After cleaning the seam with industrial ketone, the crack is scraped with epoxy cement. The color of epoxy resin daub should be the color of cement and try to be the same as that of the original concrete. 
Second, crack grouting construction technology. The concrete around the crack shall be chipped away. The chipping direction shall conform to the direction of the crack. The chipping shall be carried out until all the reinforcement is exposed. The steel reinforcement shall be derusted manually, and the gouged groove shall be blown or washed by air compressor or high-pressure water gun. The dust and scum in the notch are cleaned to expose the steel bars and fresh concrete. The exposed fresh concrete is coated with an interface agent, the exposed reinforced steel is coated with a liquid rust inhibitor, the concrete is mixed with a rust inhibitor to repair the notch, and the post-maintenance work is performed to prevent the repaired sputum from cracking again.

During the process of the jointing, the quality control should be highly valued. After the construction is completed, the quality should be self-checked. The coring method can be used to determine whether the filling effect is dense and full. If there are phenomena such as uncompacted effect of irrigation joint and re-cracking, reinforcing measures such as supplementary irrigation should be adopted to ensure construction quality. The performance indexes of grouting adhesive shall meet the requirements of national standards. The filling glue should pass the trial test mix ratio before construction. After the filling glue is prepared, it should be injected into the crack during the applicable period.

Second, exposed steel reinforcement disease. The concrete around the exposed steel reinforcement shall be chipped and removed to make the steel reinforcement exposed, and manual derusting measures shall be taken for the steel reinforcement. When the corrosion area of the main reinforcement accounts for more than $20 \%$ of the total area of the reinforcement, it is necessary to dig out all the main reinforcement and remove rust, then weld a steel reinforcement of the same diameter on the side of the main reinforcement, and finally repair and level it with polymer mortar.

\subsection{Install Operation Monitoring System}

The installation of operation monitoring system can understand the actual situation of bridges and roads in real time and master the deformation, stress and structural vibration of bridges and roads in the process of operation. Long-term and real-time monitoring of bridges and roads in a planned way is helpful to timely grasp the quality status of bridges and roads, accumulate and continue the technical and operational data of bridges and roads, and provide reference for the follow-up management and maintenance of bridges and roads.

\section{Conclusion}

With the implementation of traffic construction measures supported by the state, as well as the needs of local economic development, disease analysis and maintenance of bridges and roads are extremely important. In this study, firstly, the diseases of bridge and road are introduced. Then, the causes of the disease are analysed and the prevention measures are proposed. However, in this study, it only discusses the mechanism of bridge and road diseases from a theoretical perspective. In the following research, a more comprehensive and systematic analysis and research should be carried out on the bridge and road to provide a better reference for the construction and maintenance of roads, bridges, houses and other buildings. In addition, the operation monitoring system of bridges and roads needs more detailed research.

\section{References}

1. Kang, C., Schneider, S., Wenner, M., \& Marx, S. (2018). Development of design and construction of high-speed railway bridges in germany. Engineering Structures, 163, 184-196.

2. Karmakar, M., Leavitt, P. R., \& Patoine, A. (2018). Effects of bridge construction and wastewater effluent on phytoplankton abundance and sediment geochemistry in an atlantic temperate coastal bay since 1930. Estuaries and Coasts, 42(2), 365-377.

3. Elkawas, A. A., Hassanein, M. F., \& Elchalakani, M. (2018). Lateral-torsional buckling strength and behaviour of high-strength steel corrugated web girders for bridge construction. Thin-Walled Structures, 122, 112-123.

4. Liu, W., Dunford, M., \& Gao, B. (2018). A discursive construction of the belt and road initiative: from neoliberal to inclusive globalization. Journal of Geographical Sciences, 28(9), 1199-1214. 
5. Tauro, J. C. (2018). Editorial commentary: put down your saw and pick up your scope! or, why burn down the bridge when the road ahead is full of potholes? reverse total shoulder replacement versus arthroscopic rotator cuff repair. Arthroscopy the Journal of Arthroscopic \& Related Surgery, 34(4), 1128-1129.

6. Kużawa, M., Kamiński, T., \& Bień, J. (2018). Fatigue assessment procedure for old riveted road bridges. Archives of Civil $\backslash$ s\& $\backslash$ smechanical Engineering, 18(4), 1259-1274.

7. Wu, X., Wang, W., Chen, W., \& Ding, S. (2018). China's first road-cum-railway suspension bridge with rigid-cables of three main stiffening frames in parallel: the two-storey jinan yellow river bridge. Stahlbau, 87(3), 203-214.

8. Monreal, C. O. (2018). Intelligent vehicle technology r\&d group [its research lab]. IEEE Intelligent Transportation Systems Magazine, 10(3), 200-203.

9. Liu, A. R., \& Pi, Y. L. (2018). Seismic response of long span continuous rigid-framed steel arch bridge. Key Engineering Materials, 763, 1087-1094.

10. Nguyen-Phuoc, D. Q., Amoh-Gyimah, R., Tran, A. T. P., \& Cao, T. P. (2018). Mode choice among university students to school in danang, vietnam. Travel Behaviour \& Society, 13(1), 1-10.

11. Tauro, J. C. (2018). Editorial commentary: put down your saw and pick up your scope! or, why burn down the bridge when the road ahead is full of potholes? reverse total shoulder replacement versus arthroscopic rotator cuff repair. Arthroscopy the Journal of Arthroscopic \& Related Surgery, 34(4), 1128-1129.

12. Dhar, A., Kumar, N. S., Paul, P. K., Roy, S., \& Vekariya, R. L. (2018). Influence of tagging thiophene bridge unit on optical and electrochemical properties of coumarin based dyes for dsscs with theoretical insight. Organic Electronics, 53, 280-286.

13. Valle-Zermeño, R. D., Medina, E., Chimenos, J. M., Formosa, J., Llorente, I., \& Bastidas, D. M. (2017). Influence of mswi bottom ash used as unbound granular material on the corrosion behaviour of reinforced concrete. Journal of Material Cycles and Waste Management, 19(1), 124-133.

14. Adrian, I. R. (2017). Establishing the optimal solution for obstacle crossings. application for bridge km.14+162 placed on the bypass of bistrita city. Mathematical Modelling in Civil Engineering, 13(1), 12-20.

15. Lai, E., Gentile, C., \& Mulas, M. G. (2017). Experimental and numerical serviceability assessment of a steel suspension footbridge. Journal of Constructional Steel Research, 132(5), 16-28.

16. Chen, X., Xu, Z., Yao, L., \& Ma, N. (2018). Processing technology selection for municipal sewage treatment based on a multi-objective decision model under uncertainty. International Journal of Environmental Research \& Public Health, 15(3), 448.

17. Ghaibeh, A. A., Kasem, A., Ng, X. J., Nair, H., Hirose, J., \& Thiruchelvam, V. (2018). Gaining insights on nasopharyngeal carcinoma treatment outcome using clinical data mining techniques. Studies in Health Technology \& Informatics, 247, 386

18. Jayakesh, K., \& Suresha, S. N. (2018). Experimental investigation of interface treatment technique on interface shear bond fatigue behavior of ultra-thin whitetopping. Construction \& Building Materials, 161, 489-500.

19. Bessaim, M. M., Missoum, H., Bendani, K., \& Laredj, N. (2018). Laboratory investigation on solutes removal from artificial amended saline soil during the electrochemical treatment. International Journal of Environmental Science \& Technology (3), 1-10.

20. Cui, Y., Zhang, X., Guo, R., Zhang, H., Bo, L., \& Xie, M., et al. (2018). Construction of bi 2 o 3 /g-c 3 n 4 composite photocatalyst and its enhanced visible light photocatalytic performance and mechanism. Separation \& Purification Technology, 203, 301-309. 